\title{
Editorial
}

\section{Occupational and Environmental Medicine: on line and further developments to come: www.oem.bmjjournals.com}

Electronic publishing is here to stay. It has already made a big impact on the way journals are put out to their readers, with all the big journals now available on line as well as in paper versions. But this is just the start. Improvements in the readability and portability of electronic material are taking place incredibly fast, so that in five years paper journals may not exist at all. People will do their literature searches through their mobile telephones, making use of PubMed or something similar, and read their journals, those that still exist, on fold-over screens or electronic paper. So change is being forced on journals if they want to survive.

This offers great opportunities for medical and scientific publishing. At Occupational and Environmental Medicine we are moving forward with enthusiasm into this new era. As a first step, OEM now has a full text web site that goes live in April 2000. We have had a web site for some time but it consisted only of tables of contents and general information. We have joined the BMF, other journals in the BMJ Publishing Group, and many other important medical journals at HighWire Press, a division of Stanford University's Green Library. HighWire's mission is to "foster research and instruction by providing a more direct link between the writers and readers of scholarly materials". ${ }^{1}$ The BMF's web site (www.bmj.com) is widely held to be one of the best around and has many features that add value to the research published in the print version. The OEM web site shares many of these features. Each issue of $O E M$ will be available in full (including figures and tables). There is also a fully searchable full text archive going back to January 2000 (with portable document formats (PDFs), abstracts, and tables of contents from much earlier issues), instant, free access to Medline, and "customised @lerts”, which will automatically alert you to newly published material of particular interest to your area of research. The "collected resources" feature allows you to search quickly for material in subspecialty areas. You can also search across all the journals at HighWire Press, including fournal of Epidemiology and Community Health, Thorax and others of interest in our field. Of course, we also link directly with $e B M F$ and other journals in the BMJ Publishing Group.

Each issue of $O E M$ will be put on line at the same time as the print version is distributed; this will be particularly useful for our readers outside the United Kingdom who will not have to wait for days or weeks for their copy to arrive. Access to OEM on line will be free until July 2000.
After that it will continue to be free to subscribers to the paper fournal, including those who receive it as part of their subscription to the United Kingdom Faculty of Occupational Medicine. Discussions are under way at present about future pricing models for subscriptions to the print and electronic version of $O E M$.

We have other plans afoot for increasing the value of $O E M$ to our readers, over and above the high quality scientific papers that we will continue to publish but which will increasingly become available free on line elsewhere, through PubMed or something similar. One such development is a new section for Continuing Professional Development (CPD). The first articles in this series are due to appear in November 2000. They will be commissioned from experts in particular areas and will give a state of the art exposition, in a format designed to be interesting and readable. We carried a questionnaire about CPD in OEM at the end of 1999. Of the people who felt strongly enough to respond, most were in favour of a CPD section in the fournal and suggested various topics, most of which we will be trying to include. We also asked about the use of multiple choice questions based on the CPD articles, with the possibility that these could eventually be part of a revalidation scheme for the United Kingdom Faculty of Occupational Medicine (such a scheme will become a requirement within the next few years) and again most of our respondents supported this idea. As a result, the articles in the CPD series will be accompanied by a set of multiple choice questions, in both the paper and on line fournal.

The on line fournal offers us other possibilities for developments in OEM: letters in response to papers can be much more immediate; we could publish much lengthier papers on line with shorter versions in the paper fournal; and colour illustrations in the on line version could be included at a small additional cost. We welcome any additional suggestions that readers would like to see in $O E M$, especially to make full use of our new web site. So please contact us, either through the web site or by other means if you prefer!

ANNE COCKCROFT

Editor

April 2000

1 About HighWire Press. Highwire.stanford.edu/about.shtml 